\title{
Perto de casa, longe da avenida: representação poética das escolas nos sambas de meio-de-ano
}

\author{
Cláudia Neiva de Matos ${ }^{1}$
}

\section{Resumo}

A história das escolas de samba tem sido escrita geralmente com referência ao carnaval, investigando a organização institucional das agremiações, os desfiles e sua preparação, a poética dos sambas-enredo. Em outra via de abordagem, proponho investigar uma face mais íntima dessas entidades, buscando os sentidos que elas assumem para os respectivos artistas e comunidades fora do âmbito competitivo e monumental do carnaval. O corpus principal consiste numa centena de sambas de meio-de-ano que tematizam central ou lateralmente as duas escolas portadoras da mais antiga tradição: Portela e Mangueira. Procuro identificar comparativamente as redes metafóricas e simbólicas, os modos e motivos discursivos que constroem a auto-imagem das escolas e das comunidades nelas incorporadas. O que a análise ilumina então não é a face triunfalista oferecida ao público na avenida e na televisão, mas uma fisionomia familiar estruturada por signos de coesão psicosocial da comunidade e projetada no espelho poético-musical do samba.

Palavras-chave: escolas de samba, Mangueira, Portela.

\footnotetext{
${ }^{1}$ UFF / CNPq / PACC (UFRJ). Agradeço ao CNPq pelo apoio financeiro à pesquisa da qual participa este trabalho.
} 


\begin{abstract}
The history of samba schools has been frequently written in association with carnival events and matters, focusing, for instance, on institutional organization of parades or on samba-enredo poetics. I would like to propose a different approach: in order to get a more intimate perception about these associations, one may inquire which meanings and feelings they evoke for their own artists and communities, when considered off and beyond the monumental scene of carnival competitions. The main corpus of this research is composed by a hundred of sambas-de-meio-de-ano (those that are not performed in carnival parades) speaking about the two most traditional samba schools: Portela and Mangueira. In comparative perspective, I try to identify metaphoric and symbolic nets, features and motives that constitute the self-image of schools and their communities. What analysis may bring to the light, then, is not a triumphant face displayed to public on the avenue or TV screen, but a familiar look shaped by communitarian psychosocial signs and revealed through the poetic-musical discourse of samba.
\end{abstract}

Keywords: samba schools, Magueira, Portela.

Quem assiste hoje em dia aos desfiles de escolas de samba pode ter a impressão de que são todas iguais. Porém as escolas não possuem apenas aquela face ostentada na passarela durante o carnaval. Vistas de dentro, perto de casa e longe da avenida, elas mostram sua face singular, construída com traços que remetem a contextos, ambientes, histórias, personagens e discursos diferentes.

Para tentar apreender algo do modo particular como em cada agremiação se conjuga uma comunidade e se expressa sua história, este trabalho reuniu um corpus de sambas cujas letras referem-se explicitamente às escolas. Não os sambas-enredo cantados na avenida, mas aqueles que circulam prioritariamente dentro e em torno da própria escola: sambas de meio-de-ano, sambas de quadra e de terreiro. Para circunscrever e viabilizar a pesquisa, concentrei-me em duas escolas octogenárias, as mais antigas em atividade: Mangueira e Portela. Trabalhei com cerca de 137 sambas, alguns deles inéditos, produzidos e/ou lançados desde os anos 20 até o presente.

Das escolas que atuam hoje em dia, foram Mangueira e Portela pioneiras a desfilar e vencer na Praça Onze. Como tantas outras, constituíram-se a partir de agremiações que já existiam. Fundada oficialmente em 1929, a Mangueira formouse majoritariamente com base no bloco dos Arengueiros. A Portela derivou de diversos grupos situados na região de Oswaldo Cruz no final dos anos 20.

Como se sabe, considera-se que tenha sido a Deixa Falar a primeira agremiação carnavalesca a intitular-se "escola de samba", em 1928. Ela durou pouco, dissolvendo-se após perder o primeiro desfile competitivo de que participou, em 1932. Porém os "bambas" do grupo, como Ismael Silva e Bide, foram desde a primeira hora reconhecidos como mestres primordiais, e desde então constantemente 
lembrados e celebrados pelos sambistas mangueirenses e portelenses. Quando estes falam daqueles, contudo, nunca mencionam o nome "Deixa Falar", mas sempre o nome do bairro - o "Estácio", o "velho Estácio": "Uma escola que não devia acabar/ Era o velho/ Estácio de Sá"2.

De modo geral, antes mesmo de se constituírem como "escolas", os conjuntos de sambistas e amantes do samba situados na cidade já tinham uma cartografia estruturada e reconhecida, como a que aponta Noel Rosa em "Palpite infeliz":

Salve Estácio, Salgueiro e Mangueira

Oswaldo Cruz e Matriz

Que sempre souberam muito bem

Que a Vila não quer abafar ninguém

Só quer mostrar que faz samba também

Neste samba de 1935, Noel não está falando propriamente de escolas, mas mapeando os chamados "redutos de bambas" da época. A marca logística e topográfica vai ser fundamental na constituição do discurso sobre o samba e no sentido que será atribuído às escolas. Ela embute a metáfora da "raiz", indicando a importância do pertencimento a um território e a constituição de um campo singularizado de cultura e poder que confere à comunidade do samba traços de nobreza e distinção. Escreve Nelson Fernandes:

\begin{abstract}
A história das escolas de samba é também uma parte da história da relação dos grupos populares do Rio de Janeiro com seu espaço vivido e meio-ambiente, os bairros populares, subúrbios e favelas. Foi especialmente através desta instituição que os grupos expulsos da cidade contra-arrestaram a marginalização e a segregação político-cultural "desmoralizante", inerentes ao processo de modernização urbana do Rio de Janeiro, posto em marcha desde o final do século XIX $[\ldots] .^{3}$
\end{abstract}

A entidade escola de samba dá perfil institucional à vinculação entre uma comunidade e um lugar, um território normalmente designado no nome da agremiação: Estação Primeira de Mangueira, Acadêmicos do Salgueiro, Unidos de Vila Isabel, Mocidade Independente de Padre Miguel etc. O lugar tem nome próprio, ao qual se deve respeito e cortesia. Antes de haver as competições oficiais, a rivalidade entre os grupos sambistas e carnavalescos já existia, mas se exercia num modo fidalgo e associativo, um protocolo de convivência cordial fundada no gosto pela festa. Era muito comum os grupos visitarem-se uns aos outros.

\footnotetext{
2 "Silenciar a Mangueira não", Cartola.

${ }^{3}$ FERNANDES, Nelson da Nóbrega. Escolas de samba: sujeitos celebrantes e objetos celebrados. Rio de Janeiro: Secretaria das Culturas/ Departamento Geral de Documentação e Informação Cultural/ Arquivo Geral da Cidade do Rio de Janeiro, 2001, p. 10.
} 
Viemos da Estrada do Portela

Cumprimentar a Mangueira, o Salgueiro e a Favela

A Vizinha Faladeira e o Morro da Matriz

Pra dizer que o nosso samba é feliz ${ }^{4}$

\section{Orgulho da Mangueira}

Em 1932, começam os desfiles competitivos patrocinados pela imprensa. Os três primeiros títulos são da Mangueira, como será lembrado por Cartola: "Temos orgulho de ser os primeiros campeões" ${ }^{5}$. Também dirá Nelson Sargento: "Mangueira, eu me orgulho, me ufano de ti" 6 . O orgulho será traço constante na (auto)imagem da Mangueira, imagem freqüentemente projetada pelo discurso da "exaltação".

Disse alguém: "A gente prepara o carnaval... vem Mangueira." Na passarela, afirmam os mangueirenses, "O povo só grita 'Mangueira querida'/ E o tradicional 'Já ganhou"'7. De fato, entre as escolas, é a Estação Primeira quem goza da mística mais forte e difundida. Ela é mesmo "a mais querida"8, a que mais sambas inspirou aos mais diversos compositores e poetas.

Enquanto a Portela, conforme veremos, foi cantada aplicadamente por seus próprios integrantes, mas quase que só por eles, a Mangueira inspirou muita gente diferente, gente que não era necessariamente de lá, nem do morro. Como o malandro Wilson Batista, com seis sambas no corpus. Como Hermínio Bello de Carvalho, autor de poucos sambas, mas entre eles o antológico "Sei lá, Mangueira", em parceria com o portelense Paulinho da Viola. Como Tom Jobim e Chico Buarque, instalando seu "Piano na Mangueira". O próprio Nelson Cavaquinho, com sete sambas no corpus, embora plenamente associado à Mangueira que amorosamente cantou, não era de lá. Só saiu na escola uma vez, nos anos 70, compondo a comissão de frente com sambistas da Velha Guarda.

É que antes de existir a escola, já havia ali um reduto famoso de bambas, o "Morro de Mangueira" celebrado no samba de Manuel Dias em 1926. Mais tarde, a popularidade enraizada e duradoura da Estação Primeira não se poderá medir simplesmente em termos dos campeonatos conquistados. Foram 17 até 2005, contra 21 da Portela. Mas a exaltação à verde-e-rosa já nos anos 50 era um "inesgotável filão" que ameaçava provocar a "saturação do tema poético", segundo Edigar de Alencar?.

\footnotetext{
4 "Queremos ver", Caetano e Monarco.

5 "Sala de recepção", Cartola.

6 "Mangueira divina e maravilhosa", Nelson Sargento.

7 "Mangueira divina e maravilhosa", Nelson Sargento.

${ }^{8}$ Título de um samba de Padeirinho.

${ }^{9}$ ALENCAR, Edigar de. O carnaval carioca através da música. Rio de Janeiro: Francisco Alves; Brasília: Instituto Nacional do Livro, 1979, p. 380.
} 
No carnaval de 1974, o nome da escola encabeçava o título do enredo: "Mangueira em tempo de folclore". Assumindo a autocelebração na avenida, em 1983 a escola se torna o assunto central de seu próprio carnaval, com "Verde que te quero rosa - semente viva do samba". Depois disso, por mais sete vezes, notadamente na década de 90, Mangueira ostentará no título do enredo sua assinatura.

Em 83, o samba-enredo convocava e celebrava Cartola, falecido três anos antes:
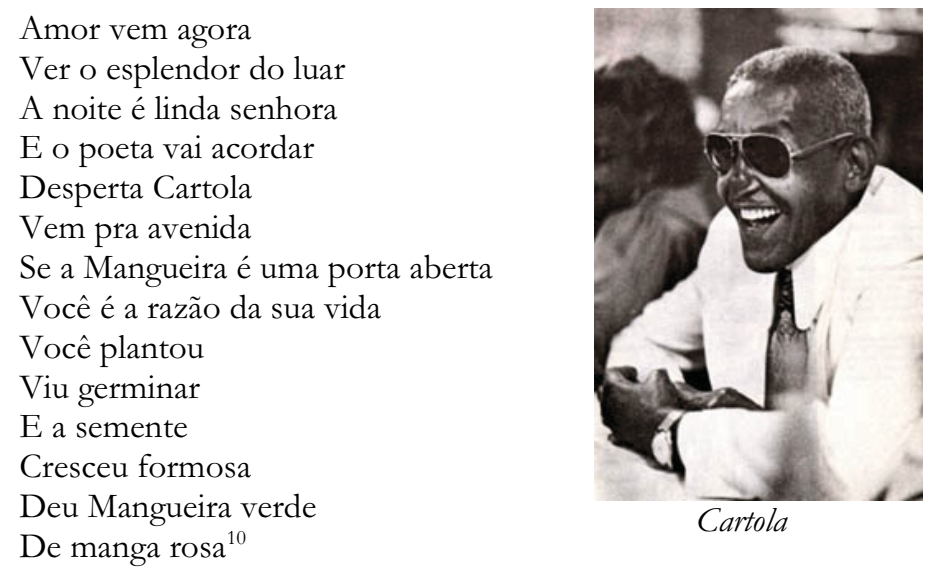

Através da figura de Cartola, era a si mesma que a escola cantava na avenida de um modo como ainda não se havia visto. Ele sempre foi, sem dúvida, o compositor mais prestigiado e mais identificado com a Mangueira, e é o que tem mais sambas - nove - no corpus verde-e-rosa. Segundo Henrique Cazes ${ }^{11}$, a sutileza e complexidade de suas harmonias influíram no estilo de outros compositores da escola, instaurando na música mangueirense uma espécie de padrão, para o qual também teria colaborado Nelson Cavaquinho. Esse padrão não pode ser apreendido no corpus deste trabalho, provavelmente devido à dispersão geográfica dos compositores ali presentes. Entretanto, apesar da heterogeneidade musical, os sambas que falam da verde-e-rosa se congregam discursivamente pelo teor celebratório e pela recorrência de certos temas e imagens, como no modelar "Exaltação à Mangueira":

\footnotetext{
${ }^{10}$ De Heraldo Faria, Geraldo Neves e Flavinho Machado.

${ }^{11}$ Em entrevista concedida a mim em 07/07/2005. Agradeço a Cazes pela sua generosa contribuição para este trabalho.
} 
Mangueira teu cenário é uma beleza

Que a natureza criou

O morro com seus barracões de zinco

Quando amanhece que esplendor

Todo mundo te conhece ao longe

Pelo som dos teus tamborins

E o rufar do teu tambor

Chegou ô ô

A Mangueira chegou ô $\hat{o}^{12}$

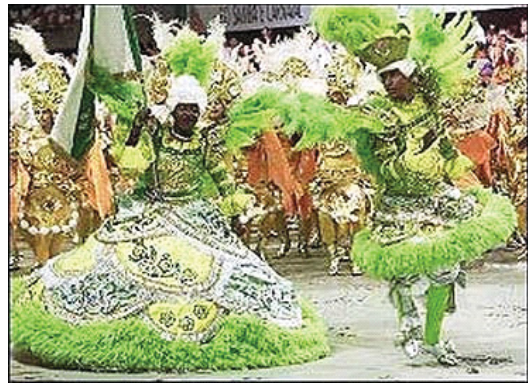

Porta-estandarte e mestre-sala da Mangueira

Antes de mais nada Mangueira é uma presença na cidade, um fato sensorial, algo que se reconhece e aprecia pela vista e pelo ouvido. Além da arte rítmicomusical, costuma-se apontar ali a obra privilegiada da natureza, uma força viva e sempre renovada.

\author{
Mangueira \\ Nasceste de uma semente \\ À beira de uma nascente \\ Você não pode morrer, não pode morrer... ${ }^{13}$
}

Com base na definição topográfica - o morro - e toponímica - o nome "Mangueira" -, constrói-se a imagística de um território abençoado e fértil, propício às efusões do lirismo e da sensualidade. "E o corpo das mulatas/ Quando veste verde-e-rosa é a Mangueira"14. O nome do morro e da escola torna-se um gerador inesgotável de metáforas orgânicas que vão da semente aos frutos, multiplicam a vida na "floresta de sambistas"15 e no "celeiro de cabrochas e bambas" ${ }^{16}$, fundando a mitologia edênica do "céu no chão"17.

Daí a facilidade e felicidade, tantas vezes afirmadas, de morar em Mangueira. A idealização do morro e da favela, como refúgio de harmonia e liberdade, morada da alegria, é tópico freqüente no samba dos anos 50 e 60 . Mangueira serve muitas vezes como referência dessa temática, vertida em imagens idílicas que exaltam a velha fórmula "um amor e uma cabana", aqui traduzida para "uma cabrocha e um barraco": Uma cabrocha e uma esteira / Um barracão de madeira / Qualquer malandro em Mangueira tem" ${ }^{\prime 18}$.

O poder da idealização poética é explicitado - sem ser problematizado por Nelson Cavaquinho:

\footnotetext{
12 "Exaltação à Mangueira", Enéas B. Silva e Aloísio Augusto Costa.

13 "Nasceste de uma semente", Zé Ramos.

14 "Verde que te quero rosa", Cartola e Dalmo Castello.

15 "Jequitibá", Zé Ramos.

16 "Mangueira divina e maravilhosa", Nelson Sargento.

17 "Sei lá Mangueira", Paulinho da Viola e Hermínio Bello de Carvalho.

18 "Mundo de zinco", Wilson Batista e Nássara.
} 
Os versos de Mangueira são modestos

Mas há sempre força de expressão

Nossos barracos são castelos

Em nossa imaginação. ${ }^{19}$

Em contraponto às vicissitudes da pobreza, a promessa de alegria resiste e se sustenta no pertencimento ao lugar e à sua gente, os quais se mostram estreita mente vinculados entre si. O vínculo entre o lugar (singular) e a comunidade (plural) está lindamente representado em "Sala de recepção", de Cartola.

Gravado pelo compositor e por sua filha Creuza, este samba construído como um diálogo enseja um jogo sutil e fluente de vozes e pessoas verbais. $\mathrm{Na} 1^{\text {a }}$ parte alguém que fala "de fora" se dirige à Mangueira na $2^{a}$ pessoa do singular.

Habitada por gente simples e tão pobre

Que só tem o sol que a todos cobre

Como podes, Mangueira, cantar?

A outra voz, que vem de Mangueira, responde inicialmente na $1^{\mathrm{a}}$ do plural, representando todo o povo do lugar:

Pois então saiba que não desejamos mais nada

A noite e a lua prateada

Silenciosa ouvem as nossas canções

Tem lá no alto um cruzeiro

Onde fazemos nossas orações

E temos orgulho de ser os primeiros campeões

$\mathrm{Na}$ pergunta enunciada, o contraste entre o lugar que canta e sua gente simples e pobre é enfatizado como dilema. Na resposta, porém, anula-se o dilema, porque o que se afirma é, justamente, a fusão entre a gente e o lugar que ela habita, ambos identificados como sujeitos que cantam. Na mesma pauta, enuncia-se o idílio entre os homens e a natureza, representada pela noite e pela lua prateada; e multiplicam-se em coro vozes e canções.

$\mathrm{Na} 2^{a}$ parte do samba, a voz que vem de Mangueira assume a $1^{a}$ pessoa do singular: o lugar e seus habitantes acham-se metonimicamente confundidos, unificados e encarnados enfim na voz do cantor/compositor, que toma a palavra.

Eu digo e afirmo que a felicidade aqui mora

$\mathrm{E}$ as outras escolas até choram

Invejando a tua condição

Ao tomar a palavra, o poeta recoloca o lugar Mangueira no foco discursivo da $2^{a}$ do singular, desta vez não mais para a pergunta, mas para o louvor e a homenagem.

19 "Sempre Mangueira", Nelson Cavaquinho e Geraldo Queiroz. 
Minha Mangueira tu és a sala de recepção

Aqui se abraça o inimigo

Como se fosse irmão

Mas a Mangueira não é puro lirismo, idílio e fidalguia. Ela participa também da ideologia da malandragem, que desde os anos 20 fez do samba seu principal suporte discursivo. Neste sentido, mesmo ficando "pertinho do céu", o morro é um reduto plenamente social e urbano. A paisagem celestial musicalizada pelos tamborins é contraponteada por visões mais realistas, como a enunciada pelo malandro Wilson Batista: "Aquele mundo de zinco que é Mangueira / Desperta com o apito do trem"... ${ }^{20}$

A mitologia e o discurso da malandragem, que incluem a Mangueira na tradição cunhada pelos bambas do Estácio, remontam até a origem da escola, no bloco dos Arengueiros. Vários compositores ligados ao morro, como Geraldo Pereira, praticaram a poética malandra. Recorda Herivelto Martins em 1954: "Eu sou do tempo em que o malandro não descia / Mas a polícia também no morro não subia"21.

Como lugar eleito, em comunicação com a cidade ao mesmo tempo que dela nitidamente demarcado, Mangueira é plenamente um "reduto": ali se nasce e morre, ali se ingressa e fica; se por força do destino dali se parte, é levando e deixando saudades.

Quem se muda pra Mangueira, é verdade

Leva a vida cheia de felicidade

Quem se muda de Mangueira tem saudade

E voltará ou mais cedo ou mais tarde ${ }^{22}$

\section{Saudades da Portela}

Nos primeiros desfiles carnavalescos, a escola de Oswaldo Cruz chamavase Vai Como Pode. Esse nome vigora até 1935, quando ela arrebata seu primeiro campeonato. No mesmo ano, é fundada a União das Escolas de Samba e o desfile ganha contornos institucionais, oficiais, regulamentares. No período getuliano préEstado Novo, cresce a intervenção das autoridades administrativas e policiais. Para receber subvenção, requer-se que os grupos carnavalescos estejam legalizados na polícia. É o que trata de fazer a Vai Como Pode, registrando-se na Delegacia de Costumes e Diversões. Mas o delegado acha inadequado o nome do grupo, e solicita ou impõe que ele seja trocado. Como a sede é no 412 da Estrada do Portela,

\footnotetext{
20 "Mundo de zinco", Wilson Batista e Nássara.

21 "Saudosa Mangueira", Herivelto Martins.

22 "Quem se muda pra Mangueira", Zé com Fome.
} 
uma das mais importantes vias de passagem dos bairros de Oswaldo Cruz e Madureira, fica sendo Grêmio Recreativo Escola de Samba da Portela.

Por isso diria o samba: "A rua já lhe empresta o nome / Eu também lhe dou minha canção"23. Diferentemente de Mangueira, Portela não designava um reduto de bambas, no sentido territorial. O reduto era Oswaldo Cruz. Mas o termo Portela, antes mesmo de denominar a escola e remeter ao seu endereço, ficara conhecido como alcunha de seu principal líder, Paulo Benjamin de Oliveira, o Paulo da Portela. O verdadeiro mapa da Portela foi sendo traçado pelos nomes de seus grandes personagens, dirigentes famosos e respeitados, compositores férteis e brilhantes. O rosto da Mangueira desenha-se num certo espaço; já o da Portela surge nas linhas do tempo, como sugerem Monarco e Chico Santana:
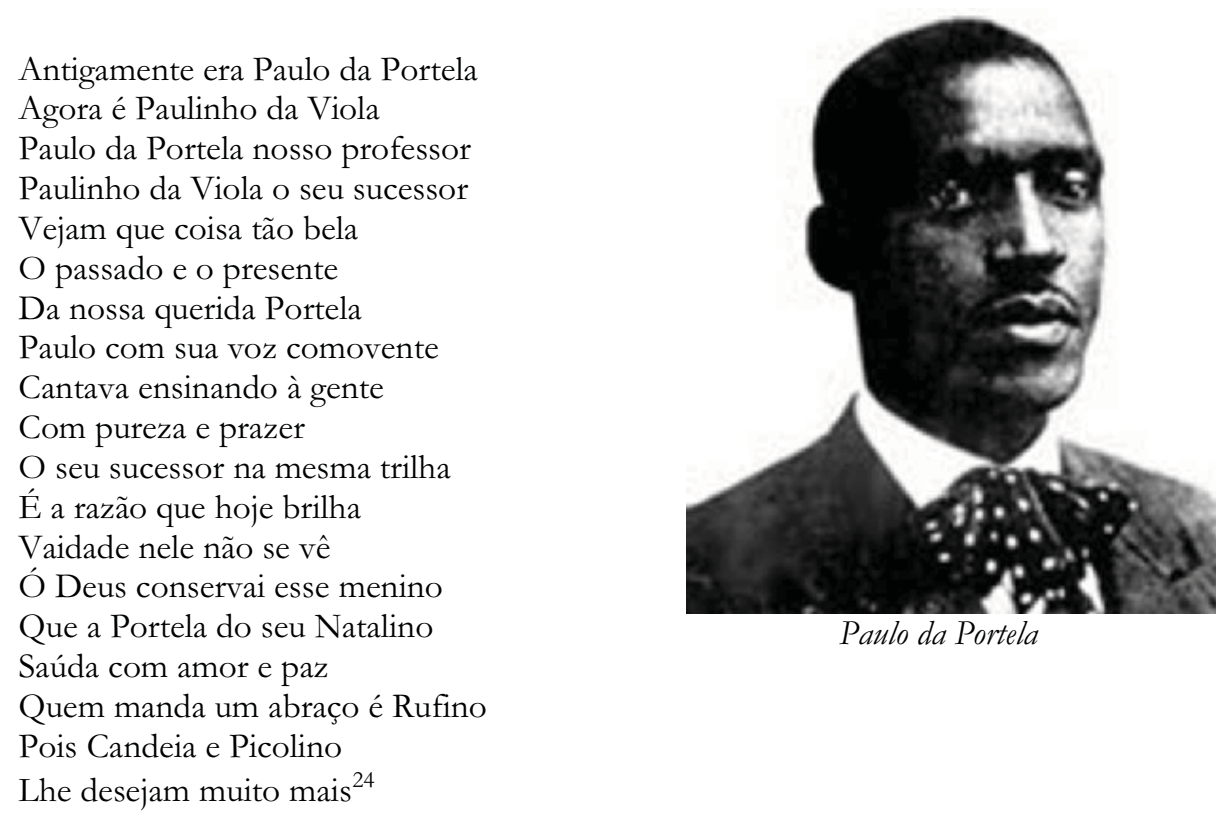

No início do século XX a região de Oswaldo Cruz e Madureira parecia uma cidade do interior. Os primeiros moradores oriundos do centro da cidade vieram chegando a partir de 1910. A propósito do já citado samba de Noel Rosa que nomeia "Estácio, Salgueiro e Mangueira/ Oswaldo Cruz e Matriz", Sérgio Cabral ${ }^{25}$ lembra que, desses lugares, só Oswaldo Cruz e o Estácio não eram morros (embora este último fosse associado ao Morro de São Carlos). O bairro da Vai Como Pode era também o único realmente distante do coração da cidade. A Portela ficava longe, às vezes para os próprios portelenses, como sugere o velho refrão de Antonio Rufino: "Levanta cedo, trata de te preparar/ Vamos pra Portela que o reino

\footnotetext{
23 "Portela é uma família reunida", Monarco e Candeia.

24 "De Paulo da Portela a Paulinho da Viola", Monarco e Chico Santana.

${ }^{25}$ CABRAL, Sérgio. As escolas de samba: o quê, quem, como, quando e por quê. Rio de Janeiro: Fontana, 1974, p. 61.
} 
do samba é lá"26. Na Mangueira se pode viver; à Portela é preciso ir, atendendo ao apelo do samba: "Chegou a hora de caminhar eu vou / Vou pra Portela que o samba já me chamou"27.

Nos primeiros tempos do samba carioca, Estácio, Mangueira e Oswaldo Cruz formavam a tríade toponímica de maior prestígio, sintetizando a geografia sambista da cidade: o morro, a esquina, o subúrbio. Porém Estácio e Mangueira eram mais citadinos, mais aproximados pela topologia e pela mítica da malandragem. O pessoal de Oswaldo Cruz sempre foi mais provinciano, talvez mais sério e conservador, com um traço rural que marcou o "som da Portela", como apontam Vargens e Monte:

Estabelecia-se uma fusão: de um lado, o som das populações rurais de origem negra, traduzido no uso dos instrumentos de percussão típicos de suas manifestações religiosas e festivas, representadas pelos toques rituais, pelo batuque, pelo jongo e pelo caxambu; de outro, as influências dos sons oriundos do centro da cidade, levados pelos habitantes da Pedra do Sal, do morro da Favela e do Estácio: os desfiles dos ranchos, os cordões, os sambas de roda, os pastoris, os ternos de Reis e as rodas de capoeira. [...] consolidouse uma unidade marcada pelas lembranças rurais nas letras, na divisão e no ritmo dos sambas, destacando-se os pandeiros, surdos e chocalhos. $^{28}$

A Mangueira nasceu no morro; a Portela construiu-se no subúrbio como agremiação escolar. Em vez da mitologia da malandragem, o que vicejou ali foi um discurso consagrando a educação, a disciplina, a distinção compatíveis com quem freqüenta a escola. Na sua poética, os motivos recorrentes do "professor" e do "livro" aparecem como mantenedores e veiculadores da tradição. Já em 1939 Paulo da Portela propõe seu "Teste ao samba":

\author{
Vou começar a aula \\ Perante a Comissão \\ Muita atenção, eu quero ver \\ Se diplomá-los posso ${ }^{29}$
}

Como "civilizador do samba", Paulo exige boa aparência, boa conduta e boa linguagem dos integrantes da escola. Nas composições alterna um estilo simples e coloquial com seu estilo de orador rebuscado. Em sua homenagem serão compostos numerosos sambas, principalmente por ocasião de sua morte, em 1949.

\footnotetext{
26 "Levanta cedo", Antonio Rufino.

27 "Chegou a hora de caminhar", Chico Santana.

${ }^{28}$ VARGENS, João Baptista M. \& MONTE, Carlos. A Velha Guarda da Portela. Rio de Janeiro: Manati, 2001, pp. 35-36.

29 "Teste ao samba", Paulo da Portela.
} 
Apesar de ter poucas composições gravadas em vida, contribuiu provavelmente mais do que ninguém para que a Portela se estruturasse ideológica e poeticamente como instituição, "academia do samba" onde se escreve e se aprende uma história articulada em torno de figuras exemplares.

O pessoal de Oswaldo Cruz seguiu a lição e foi aprovado com louvor, liderando os campeonatos durante três décadas. Foram 17 vitórias entre 1941 e 1970, contra 7 da vice-líder Mangueira. Mas em seguida decaiu radicalmente, vencendo apenas em 80 e 84. Para completar a crise, 1984 foi também o ano do cisma que levou dissidentes a fundarem a escola Tradição.

No mesmo momento em que se iniciava o declínio da escola, um grupo de compositores e músicos veteranos reuniu-se para formar o conjunto Velha Guarda da Portela. Por iniciativa e apadrinhamento de Paulinho da Viola, lançaram em 1970 o disco Portela, passado de glória. Seria o primeiro e mais bem sucedido grupo de Velha Guarda organizado como equipe para espetáculos e gravações. Segundo Martinho da Vila ${ }^{30}$ :

\footnotetext{
A Velha Guarda da Portela é diferente porque se organizou em torno de compositores. [...] Os membros da Velha Guarda são a essência da Portela. [...] O nome da Portela é importante para a manutenção do conjunto.
}

A orientação de Paulo é ainda hoje assumida pelos membros da Velha Guarda, para quem ele encarnou o primeiro, principal e sempre saudoso professor, como destaca Monarco:

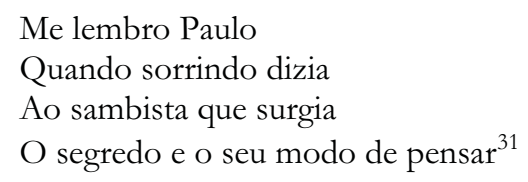

Apesar de ser, na época de sua formação, um dos mais jovens do grupo, Monarco será o maior mentor da poética portelense, conforme configurada e perpetuada no estilo da Velha Guarda. É o grande cantor da Portela, com nada menos de 17 sambas no corpus - alguns em parceria póstuma com Paulo da Portela. É nos seus versos que mais se insiste sobre a tradição, a história, os nomes cultuados, contribuindo para criar uma imagem fortemente referenciada no passado e na saudade.

\footnotetext{
${ }^{30}$ Apud VARGENS, João Baptista M. \& MONTE, Carlos, op. cit., p. 42.

31 "Portela desde que eu nasci", Monarco.
} 
Portela

Minha querida Portela

Sinto saudade daquelas

Lindas noites de luar

Saudades

Do saudoso Natalino

Paulo Alcides Rufino

Quando vinham ensaiar

Pastoras

Como dona Bernardina

Niete Alice Braulina

E a saudosa Dagmar ${ }^{32}$

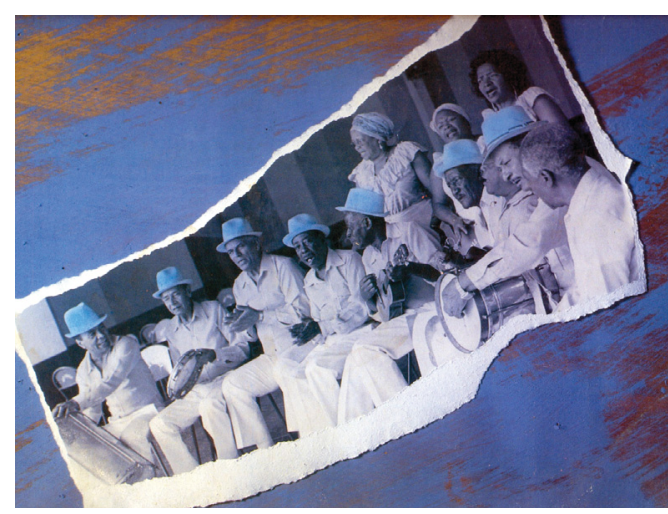

Velha Guarda da Portela

A vocação para a emulação e o espírito de grupo fizeram também com que a Portela desenvolvesse um estilo musical próprio, fortemente apoiado na tradição e marcado pela influência de certos compositores - principalmente, segundo Henrique Cazes, Chico Santana. Daí o "som" inconfundível da Velha Guarda. No corpus referente à Portela, como vimos, a concentração de autores é muito mais pronunciada que na Mangueira. A maioria dos sambas homenageando a Portela foi feita e gravada por pessoas diretamente ligadas à escola, principalmente a própria Velha Guarda.

Nas letras, o louvor da escola e dos mestres do passado se combina à reflexão moral que prega a fidelidade e questiona a vaidade. Esses tópicos são especialmente significativos numa escola que, depois de ter sido supercampeã, amarga mais de 20 anos sem o gosto da vitória. Assim, se um portelense pode dizer que "só a Portela / Sabe ganhar e perder" ${ }^{33}$, outro retruca: "Vitória para a Portela era banalidade / Mas da vitória / Estou sentindo saudade"34.

Concentrada em si mesma e voltada para o passado, é como se ela preservasse a auto-estima desenvolvendo um delicado lirismo saudosista, de gosto às vezes quase lusitano:

Hoje essa Portela que vocês ouvem falar O mundo inteiro soube consagrar

Mesmo derrotados cantaremos com alegria Essa nossa doce melodia ${ }^{35}$

"Portela é uma família reunida", diz o samba de Monarco. Não oferece, como a Mangueira, um espaço abençoado, uma beleza de cenário; mas constrói uma cadeia de símbolos, estruturada águia, o hino, o livro e o "pavilhão tão alta-

\footnotetext{
32 "Saudades da Portela", Monarco.

33 "Vaidade de um sambista", Chico Santana.

34 "Lamento de um portelense", Argemiro e Chico Santana .

35 "Chegou quem faltava", Nilson Gonçalves.
} 
neiro / Acima do ganhar e do perder" ${ }^{36}$. É no tempo que se cultiva essa história preciosa, que provoca a reflexão, a memória e a narrativa:

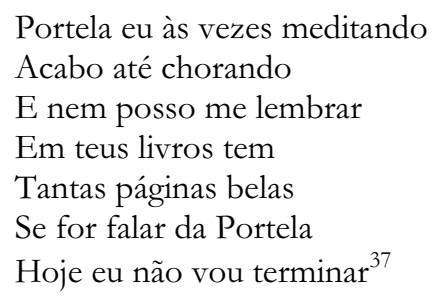

Para todavia concluir, podemos observar que as energias das duas escolas mais tradicionais se complementam mais do que rivalizam, como ensina o samba de Cartola - da Mangueira - gravado por Monarco - da Portela:

Silenciar a Mangueira, não

Disse alguém

Uma andorinha só não faz verão também

Devemos ter adversários como Oswaldo Cruz

Diz o provérbio: da discussão é que nasce a luz ${ }^{38}$

Ou como sugere Zé Keti, que ainda menino freqüentou a Mangueira, mudou-se para Bento Ribeiro e integrou a ala dos compositores da Portela, finalmente retornou à cidade e às rodas mangueirenses:

Se eu não fosse portelense

Eu seria mangueirense (tá na cara) [...]

Mangueira eu queria viver pra você

Ah se eu pudesse seria um prazer

Mas é na Portela que eu quero morrer $^{39}$

\section{Referências bibliográficas}

ALENCAR, Edigar de. O carnaval carioca através da música. Rio de Janeiro: Francisco Alves; Brasília: Instituto Nacional do Livro, 1979.

CABRAL, Sérgio. As escolas de samba: o quê, quem, como, quando e por quê. Rio de Janeiro: Fontana, 1974.

\footnotetext{
36 "Portela é uma família reunida", Candeia e Monarco.

37 "Passado de glória", Monarco.

38 "Silenciar a Mangueira", Cartola.

39 "Quero morrer na Portela", Zé Keti.
} 
CAZES, Henrique. Monarco, voz e memória do samba. Rio de Janeiro: Relume Dumará/ Prefeitura da Cidade do Rio de Janeiro, 2003.

FERNANDES, Nelson da Nóbrega. Escolas de samba: sujeitos celebrantes e objetos celebrados. Rio de Janeiro: Secretaria das Culturas/ Departamento Geral de Documentação e Informação Cultural/ Arquivo Geral da Cidade do Rio de Janeiro, 2001.

SILVA, Marília T. Barboza da; OLIVEIRA Fº, Arthur; Carlos Cachaça. Fala Mangueira. Rio de Janeiro: José Olympio, 1980.

SILVA, Marília T. Barboza da; SANTOS, Lygia. Paulo da Portela: traço de união entre duas culturas. Rio de Janeiro: Funarte, 1979.

VARGENS, João Baptista M. \& MONTE, Carlos. A Velha Guarda da Portela. Rio de Janeiro: Manati, 2001. 